\title{
Performance Analysis of the Aeration Valves and Its Protections at the Generating Units in ITAIPU Hydroelectric Power Plant
}

\author{
João Maria Marra ${ }^{1}$, Lucas Rafael Hara Motta ${ }^{2}$ and Liliana Madalena Gramani ${ }^{3}$ \\ 1. Department of Maintenance Engineering, Itaipu Binacional, Foz do Iguaçu 85856-970, Brazil \\ 2. Department of Mechanical Engineering, Western Parana State University, Foz do Iguaçu 85857-900, Brazil \\ 3. Department of Mathematics, Federal University of Parana, Curitiba 80210-170, Brazil
}

Received: April 02, 2014 / Accepted: April 18, 2014 / Published: July 25, 2014.

\begin{abstract}
With the growing energetic need present in the world, it is increasingly necessary for the researches and facilities to seek a better use of renewable natural resources. This paper is applied in the study of the performance of the aeration system of the Francis turbines present in Itaipu Hydroelectric Power Plant. When a Francis turbine operates off its optimal conditions, a vortex is formed inside the draft tube that, besides produces cavitation and pressure fluctuations, can pulse at frequencies with risk of resonance with hydraulic system, producing efforts and vibrations that may cause structural failures in the turbines, generators and civil parts of the power house. These damaging effects can be reduced using atmospheric aeration of the turbines. Because of this, the availability and effectively of the aeration system is fundamental to smooth the behavior of the turbines, helping preserve the health of the power plant. An analysis of the performance of the aeration system will be done using maintenance records and disturbances analysis reports (RAP), allowing verification of the operating conditions of the turbine and fatality of water inlet in air pipes. Through the improvements detected, it is possible to reduce machine stoppages by tripping, thus increasing the availability of the turbines.
\end{abstract}

Key words: turbine, aeration, performance.

\section{Introduction}

The energetic capacity throughout the world is increasingly growing. In the year of 2010, the United States led the ranking with 1,039 gigawatt of installed capacity, followed by China with 998 gigawatt and Japan with 287 GW. Holding the ninth place, Brazil had an installed capacity of $114 \mathrm{GW}$, which main energetic sources were hydroelectric, thermal, biomass, nuclear and wind power.

The predominant energy source in Brazil is the hydroelectric, with a installed capacity of 81 gigawatt, a number that put the country in second at the world rank, losing only for China with 219 gigawatt of

Corresponding author: João Maria Marra, Ph.D. student, engineer, research field: computational fluid dynamics. E-mail: marra@itaipu.gov.br. installed capacity [1]. A comparison among countries and its energetic sources is shown in Fig. 1.

With the growing energetic need in the world comes the necessity to research developments seeking a better use of renewable natural resources. Brazil is the holder of one of the biggest existing hydrous potential and, therefore, it is indispensable the good operation of the country's hydroelectric power plants.

The most important hydroelectric power plant in Brazil is the Itaipu Binacional, with 20 generating units, providing 14,000 megawatt and assuring the rank of biggest hydroelectric power plant in clean and renewable energy production of the world. With this generation, currently Itaipu supplies $17 \%$ of the demand of electrical energy on Brazil and $75 \%$ of Paraguay correspondently [2]. 

Generating Units in ITAIPU Hydroelectric Power Plant

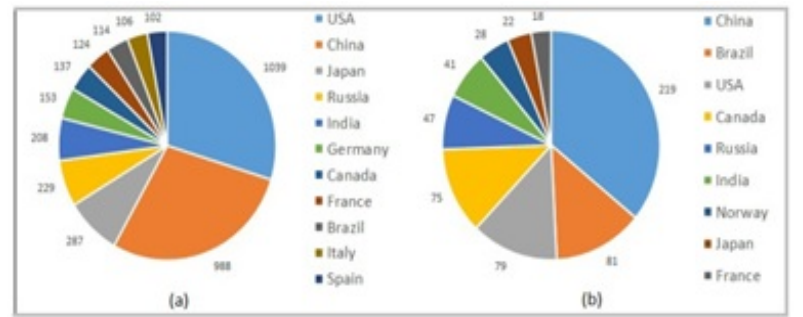

Fig. 1 (a) Total and (b) hidroelectric energetic installed capacity in 2010.

The hydroelectric plants are versatile in meeting the load variations in the SIN (interconnected system). However, either hydrological or systemic issues they have to operate outside their optimal hydraulic conditions.

Hydraulic machines are used since antiquity to convert water's kinetic and potential energy into other forms of energy, like watermills, used since ancient Greece. Unlike pumps, which provide energy to the fluid, turbines extract the fluid's energy through a component called rotor, wheel or runner via a set of vanes, blades or buckets mounted on the wheel [3].

Although, factors that reduce the eficiency, cause structural damage or even failure of the turbines are frequent and, most of time, impossible to eliminate. One example is the vortexes generated in the draft tube that may cause severe damage to the turbine's structure and foundations. Therefore, methods must be proposed and studied to minimize these effects and increase to maximum the turbine's operative availability.

The paper is organized as follows: Section 2 describes the hydraulics phenomena in Itaipu turbines, its effects and the aeration system used to smooth its behavior; Section 3 is dedicated to present the aeration valves installed; Section 4 shows the kind of devices of protection used; Section 5 analyses one attempt of modification of the aeration systems operation philosophy during faults; Section 6 discusses the performance of the aeration system; and Section 7 gives the conclusions and comments about future work.

\section{Problem Description and the Use of Aeration Systems}

\subsection{Core Vortexes}

In hydraulic turbines with a Francis rotor, the same used in Itaipu power plant, occurs two main kinds of phenomenon at the draft tube, called low load vortex (helical vortex or vortex rope) and the full load vortex (an oblong vortex). These core vortexes consist of a low pressure volume of water vapor, how illustrated in Fig. 2 referent the reduced model tests of Itaipu turbines. Both represent a forced dynamic excitation to the hydraulic system caused by the movement of these vortexes in the flow below the turbine. The full load vortex is a balanced radial pulsating volume and the low load vortex is a radial and axial unbalanced volume due to the turning of its helical volume.

When analyzing the velocity triangle in the turbine's blade, it is possible to easily understand how this swirling is formed. Francis turbines working at optimal project conditions have a purely axial exit water flow, as shown in Fig. 3, however, when working at partial or full load, i.e., not optimal conditions, the fluid exiting the turbine wheel has a tangential velocity component $V_{t}$, creating a tendency in the fluid to swirl.

The effects of partial and full load in velocity and vortex formation can be easily understood by analysing the velocity triangle in the turbine's blade trailing edge, shown in Fig. 3. $V_{\text {linear }}$ is the velocity component due to the rotation of the turbine and

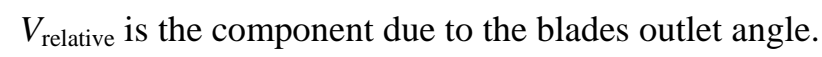
The composition of these results at the axial $V_{\text {efective }}$ velocity that is vertical on vertical Francis turbines.

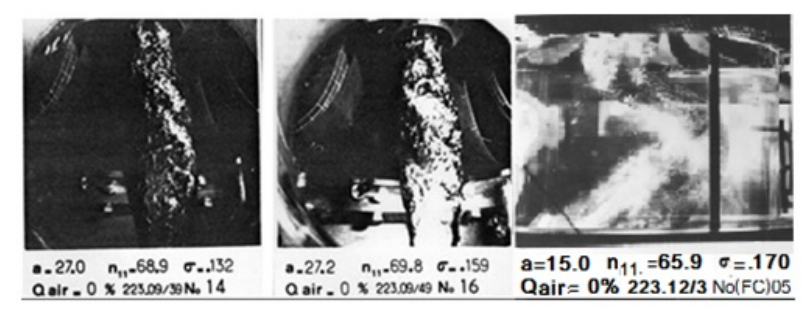

Fig. 2 Vortex rope formed in the draft tube. 


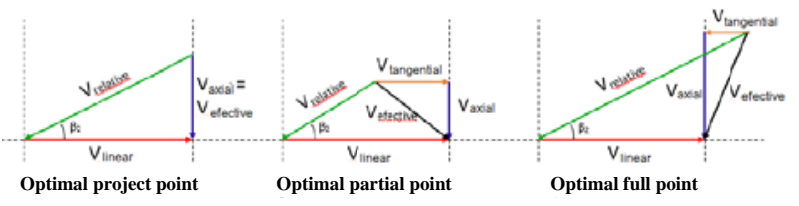

Fig. 3 Velocity triangle at runner's blades.

At partial load the relative velocity is reduced, decreasing the axial and effective velocities. A tangential velocity then appears in the same direction the turbine rotates and a helical vortex is created rotating at the same way the water.

However, when working at full load, the relative, axial and effective velocities increase. The tangential velocity component has a opposite direction than the linear velocity and the created vortex tends to rotate in the opposite direction of the water and acquire a bulb-like shape.

A low pressure region is created when the turbine is working in partial and full load. This region, summed with the vortex pulsation, may cause instabilities or resonances at the hydraulic circuit, beyond produces cavitation that may cause severe damage to the turbine's structure and shorten its life.

\subsection{Vortex Effects in Itaipu Power Plant}

Itaipu's turbine's optimal operation points are when the wicket gate is around $68 \%$ opened, with a net head turbine $118.4 \mathrm{~m}$ and a turbine output of $715 \mathrm{MW}$ [4]. Therefore, when operating far distant enough from that point, hydraulic instability or abnormal pressure fluctuation is possible to happen if the turbine's aeration is not available.

When the wicket gate opening (Ao) is under $30 \%$, unorganized vortexes are present. For a range of 30\% $<$ Ao < 50\%, partial load vortexes occur. When operating in a range next to the optimal project point, i.e., $60 \%<A o<80 \%$, there are no significative disturbances in the turbine. Full load vortexes appear when the wicket gate opening is above $80 \%$ [5].

Partial load vortexes have a frequency next to 0.35 $\mathrm{Hz}$ in Itaipu turbine's. It is cavitating and creates a lateral imbalance of forces that amplifies the shaft radial oscillations.

In Itaipu power plant, the cavitation problem was solved through the combination of four factors:

- Appropriate Thoma coeficient: the Thoma coeficient is a parameter that allows the verification of occurrence of cavitation in a particular turbine, depending only on its project and installation. In other words, the elevation where the turbine is installed modifies the Thoma number and the cavitation can be theoretically eliminated;

- Optimization of the hydraulic profile: even though the project of the turbine is such the Thoma number indicates no cavitation, in practice it is not true. Therefore, through a study of the hydraulic profile and reduced scale models, it is possible to reduce even more the effects of cavitation;

- Turbine operating range: the turbine operating range is almost always in the normal range for Francis turbines;

- Injection of compressed air: in the turbines of units U01, U02 and U03 there is a compressed air injection system and a inoxidable extended overlay at critical cavitation parts of the wheel that, when in low load (operating range where cavitation occurs) that reduce the cavitation effects.

However, the biggest problem is when the machines are operating at full load conditions or high load range. In those cases, the vortex has a frequency, besides being cavitating, it pulsates near the eigenfrequency of the hydraulic system. This phenomenon causes an excitation of the water that without aeration can reach high level of pressure fluctuation, with potential causing accelerated detrition in involved equipments and structure and could even lead to a breakage of the structure where the water flows [4].

The frequency of vortex pulsations varies relative to the head or NPSH, how indicated in Fig. 4. At rated net head $(112.9 \mathrm{~m})$ this frequency is around $1.2 \mathrm{~Hz}$.

To attenuate the vortex effects, atmospheric air can be introduced into the turbine through an aeration 


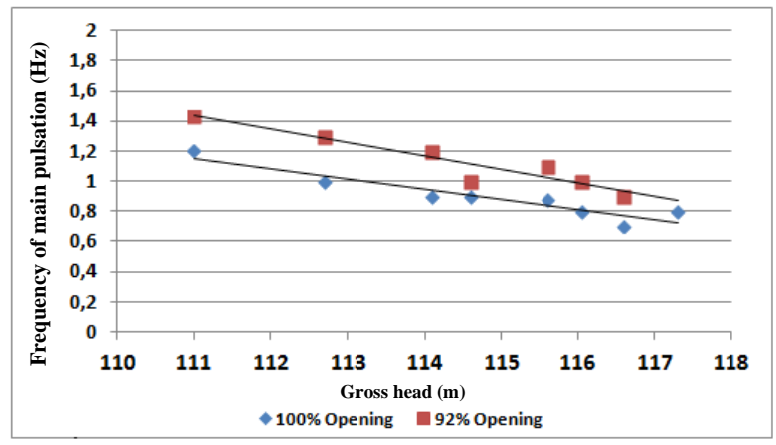

Fig. 4 Frequency variation of the full load vortex.

system. This would increase the pressure inside vortex and, consequently, reduce its pulsation amplitude and consequentely the risk of hydraulic instabilities at the penstock. However, it is important to determinate the quantity of air because of its efficiency reduction effects. These losses can, in a great amount of operation points, reach a value of $1 \%$ to $3 \%$ [6].

Furthermore, the aeration system can reduce the cavitation noise and smooth the operation, controlling hydraulics instability and resonance. Finally, the real motive of the aeration systems installed at the ITAIPU turbines is due the risk of hydraulic instability at the penstocks at full load range.

\subsection{Itaipu’s Aeration System}

Itaipu's aeration system is a classical axial aeration system and basically consists in two aeration ducts, one drainage duct, an aeration mechanical valve and its labyrinth and a main duct, linking the valve and the turbine wheel, as shown in Fig. 5.

The aeration ducts captures atmospheric air in EL. 89 of the anti-flood gallery of the power house and conduces it to turbine through the aeration valve. Each aeration duct has a motorized butterfly valve that operates usually opened, being automatically closed when the unit is stopped. By having a pre-load applied, the valve's activation is based in the low pressure inside the vortex core in the draft tube. In other words, the valve will only activate when the pressure just below the turbine wheel at the entrance of the draft tube is low enough to win the pre-load applied in the valve.

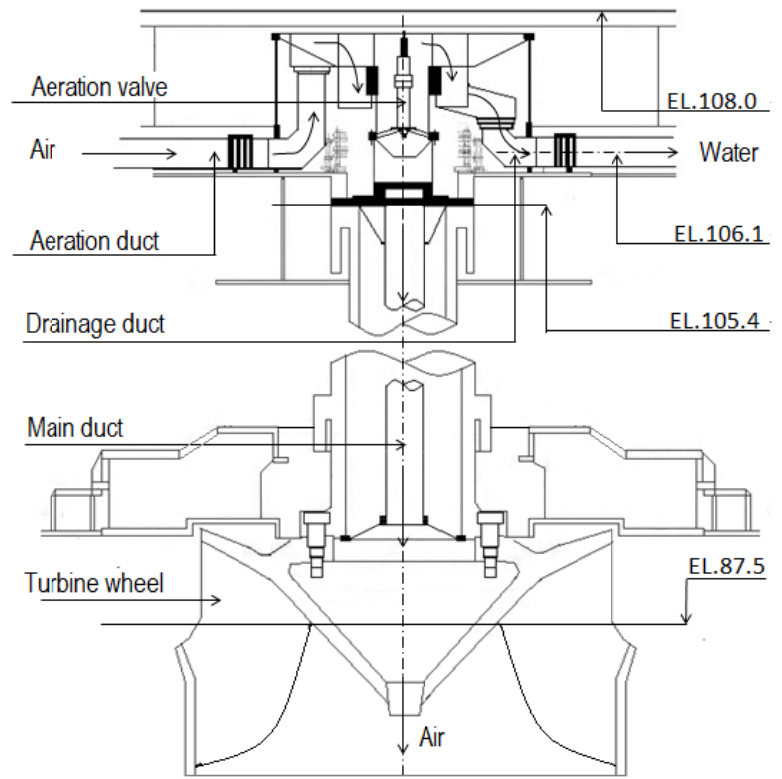

Fig. 5 Scheme of the axial aeration system of the turbines.

The connection between the stationary part and the rotating part of the aeration box is through stationary and rotative labyrinths, theoretically dimensioned to be tight until a downstream level of $138 \mathrm{~m}$ [7].

Although theoretically speaking, everything is perfect, in practice the tightness of the labyrinths can be won when the turbine is stopped. The water that manages to pass the labyrinths must be conduced out of the aeration box, which is done through the drainage duct.

The air passing through the valve is conduced centrally for the bottom part of the turbine wheel through the main duct, located inside the hollow shaft of the rotating part.

It is important to notice that the downstream elevation can be above the valve's and, in case of a valve failure, water can enter the aeration system and leak to the unit's electrical and mechanical equipment. When that happens, the valve's electrical protections stop the turbine by tripping.

For other side, when the valve is normal its obturator is hermetic and a column of compressed air inside the main duct stays retained below the valve when it it is closed, avoiding that water reaches the valve for any downstream level. 


\section{Aeration Valve of Itaipu Turbines'}

Acting as the core of the aeration system, the aeration valve is a device that allows or interrupts air supply to the draft tube. Its shaft has three self-lubricating bearings and its axial movements are damped by oil dashpots.

To prevent eficiency loss, the air flow through the valve is limited to a maximum of $2 \%$ (at atmospheric pressure) of the water flow in the turbine. A more detailed view of the valve can be seen in Fig. 6 .

Installed on top of the generator shaft (EL. 106.35), the valve was projected to start opening under a vacuum of $4,903 \mathrm{~N} / \mathrm{m}^{2}$ and be fully opened under $15,690 \mathrm{~N} / \mathrm{m}^{2}$. Using the area shown in Fig. 6, it is possible to calculate the forces corresponding to the mentioned pressures. Therefore, for an area $\mathrm{A}=0.276$ $\mathrm{m}^{2}$, the forces found were:

$$
\left(\begin{array}{c}
F_{o} \\
F_{f o}
\end{array}\right)=\left(\begin{array}{c}
1,343 \mathrm{~N} \\
4,330 \mathrm{~N}
\end{array}\right)
$$

where, $F_{o}$ is the necessary force to start open the valve and $F_{f o}$ is the minimum force acting on the valve to keep it fully opened.

In full load range, operation region studied in this paper, the valve should open in a range from heads between $102 \mathrm{~m}$ to $126.7 \mathrm{~m}$. To lower net heads, the valve does not open, however, the vortex in the draft tube is drastically reduced or non-existent [7].

\section{Protection and Alarms of the Aeration Valve}

The aeration system can be very useful by reducing the turbine instabilities, however, if operation and maintenance conditions are adverse, even catastrophic failures can happen.

The aeration valve's main purpose, as already said, is to allow atmospheric air into the turbine. But, in some conditions of downstream level and distributor opening, water from the turbine can rise until the valve's level and even go thought it, if the the valve is failed [8].

One of the characteristics of this valve is sealing the

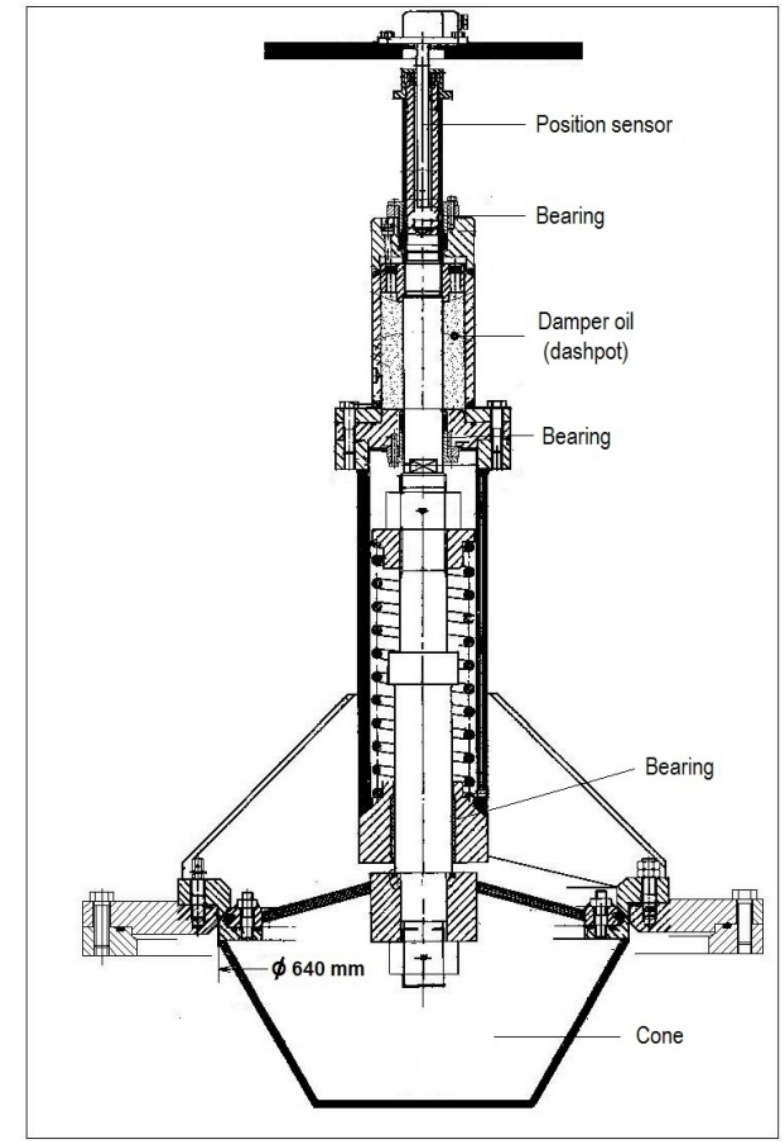

Fig. 6 Aeration valve.

pipe in which it is installed. If this sealing is compromised or the valve fails letting water go through it, there is a high chance of occurring water leakage to the generator's components (e.g., slip ring, rotor and bearings).

To prevent this leakage from occurring, sensors were installed in the aeration and drainage pipes as shown in Fig. 7. Those sensors are level sensors, detecting the presence of water and, after a certain value, send a signal to a relay that shuts down the turbine (trip).

The sensor in the drainage pipe is named 71WA and the sensor in the air admission pipe is named $71 \mathrm{AH}$. These, when actuated, send a trip signal to relays $86 \mathrm{~N}$ and $86 \mathrm{E}$, respectively. Relays number 86 are lockout relays, this means that, during a fault condition, it locks out the breakers to prevent re-energizing the system and, after that, they can only be reset manually. 


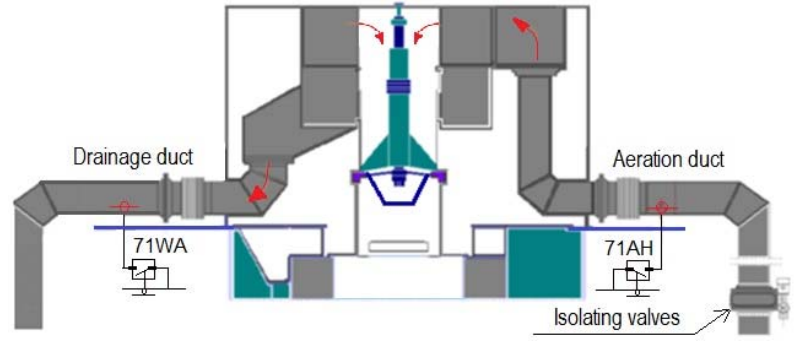

Fig. 7 Case study of aeration valve failure.

\section{Case Study of Aeration Valve Failure}

According to the philosophy of the aeration system design, the isolating valves motorized of the aeration pipes indicated in Fig. 7 are automatically closed when a blockage of the generating unit occurs and shall remain closed after the generating unit stop.

If the valve was working normally, it would be closed, preventing water to enter the aeration box and leak to the generator's components. However, if it is failed, water would pass through it and reach the aeration and drainage ducts. With the machine stopped, the labyrinth tightness is non effective and a flow of water takes place in the drainage duct.

However, at this situation the aeration box is pressurized by downstream level. Searching for reduce the water pressure in this housing under aeration valve fault condition was made an evaluation of the change effects of this philosophy. This study was made considering the generating unit fully stopped.

To find the water flow in each duct, Bernoulli's equation was used considering two sections: one at the downstream river level (1) and the other at the end of each duct (2):

$$
z_{1}+\frac{v_{1}^{2}}{2 g}+\frac{P_{1}}{\gamma}=z_{2}+\frac{v_{2}^{2}}{2 g}+\frac{P_{2}}{\gamma}+H_{l}
$$

where, $z_{i}$ is the elevation (m), $v_{i}$ is the fuid velocity $(\mathrm{m} / \mathrm{s})$ and $P_{i}$ is the pressure $(\mathrm{Pa})$ of each section (for $i$ $=1,2), g$ is the gravitational acceleration $\left(\mathrm{m} / \mathrm{s}^{2}\right)$, is the specific weigh of the fluid $\left(\mathrm{N} / \mathrm{m}^{3}\right)$ and $H_{l}$ is the head loss (m) considered through Sections 1 and 2 and calculated using Eq. (3).

$$
H_{l}=H_{m a}+\sum H_{m i}
$$

where, $H_{m i}$ are the minor head losses, calculated using Eq. (4) and $H_{m a}$ is the major head loss, calculated using Darcy-Weisbach's equation (Eq. (5)).

$$
\begin{aligned}
& H_{m i}=K * \frac{v^{2}}{2 g} \\
& H_{m a}=f \frac{L}{D} * \frac{v^{2}}{2 g}
\end{aligned}
$$

where, $K$ is the loss coeficient, $f$ is the Darcy friction factor approximated using the Moody diagram, $L$ the tube length (m) and $D$ the tube diameter (m).

Minor head losses were considered for the wheel, aeration valve, labyrinth, entrances and elbows of drainage and aeration ducts and the butterfly valve in the aeration ducts.

From the downstream river level until the entrance of the main duct in the turbine wheel, head loss was not considered for it is approximately zero. Specific weight used is from water at $20{ }^{\circ} \mathrm{C}$, therefore $\gamma=$ $9,789 \mathrm{~N} / \mathrm{m}^{3}$, for a gravitational acceleration of $g=$ $9.81 \mathrm{~m} / \mathrm{s}^{2}$.

The relation between the area of each minor loss and the water flow is given in Eq. (6).

$$
Q=v \cdot A
$$

where, $Q$ is the flow $\left(\mathrm{m}^{3} / \mathrm{s}\right)$ and $A$ is the area $\left(\mathrm{m}^{2}\right)$.

Using the equations shown was possible to calculate the maximums flow through aeration valve and the pressure in the aeration box, where three cases were studied with the following results for a downstream level at $140 \mathrm{~m}$ :

- Case 1: both aeration ducts closed

$$
\mathrm{Q}_{1}=0.1 \mathrm{~m}^{3} / \mathrm{s} ; \mathrm{P}_{1}=3.3 \mathrm{bar} ;
$$

- Case 2: one aeration duct closed and one opened

$$
\mathrm{Q}_{2}=1.8 \mathrm{~m}^{3} / \mathrm{s} ; \mathrm{P}_{2}=1.2 \mathrm{bar} ;
$$

- Case 3: both aeration ducts opened

$$
\mathrm{Q}_{3}=2.4 \mathrm{~m}^{3} / \mathrm{s} ; \mathrm{P}_{3}=0.4 \text { bar. }
$$

Despite of the benefit of minor water pressure in the aeration box at the cases 1 and 2, decided do not change the philosophy of automatic closing of the isolating valves during actuation of the protective devices 71WA and 71AH. However, after machine shutdown the operator can analyse the general 
situation of the power plant and, if convenient, open these valves by manual command. Operating this way can avoid overcharge the drainage system of the anti flood gallery, case other abnormalities can be ocurring simultaneously [9].

\section{Performance Analysis}

To analyse the behaviour of the aeration valve and its protections Disturbance Analysis Reports (RAPs) since 1990 were used. These reports are made by the Electrical Studies and Standards Division (OPSE.DT) of Itaipu and analyse all disturbances that causes machine stoppage.

Fig. 8 shows the number of disturbances that lead to a machine stoppage by actuation of the aeration system's protections.

One can notice a high number of disturbances in the first four years. In this period (1990-1994), there was no adequate comprehension of the importance of the aeration valve in the generating units operation, therefore there was no control procedures during the maintenances of the valve. This led to many failures due to a transitory reflux (i.e., small quantities of water passing through the valve because of a high downstream level) and valve failures. These last, in most cases, because of an oil loss in the valve's damper [7].

There was a high incidence of disturbances in the year of 1998. These were most due to failure in the obturator tightness combined with rises of downstream Paraná river. This failure can cause possible inlet of water to the cone of the valve, unbalancing its axial running and increasing the energy to be absorved by the damper at valve closing movement.

The faults from 2004 onwards were basically due to failure or accidental actuation of the protections 71WA and 71AH. In a few cases, the electronic module of these protections were replaced. Preventively, the sensors were raised $50 \mathrm{~mm}$ of their original elevation, as a trial for preventing actuation

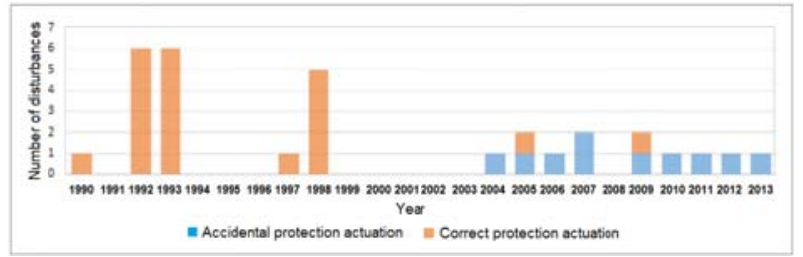

Fig. 8 Disturbances in the aeration system since 1990.

due to little and irrelevant amount of water reaching these protections.

The worst disturbance happened in 1997 and fortunatelly the unit was stopped. In such, the aeration valve's spring was broken, making impossible the valve closing. With a high downstream elevation (above the valve's elevation), water went through the valve and, as the drainage duct was unexpectedly obstructed, water leaked to slip ring, upper guide and combined bearings. That made the unit stay shut for approximately 38 days.

In short, the total number of disturbances in the aeration system since 1990 is 31 where, in 21 of them, the turbine stopped because of a correct protection actuation, while in the other 10 , there was an accidental protection actuation. A linear tendency line is also shown in Fig. 9, indicating that is decreasing as the years pass.

The median number of failures per year is 1.35 . Fig. 9 shows the median number of failures per year in groups of four years each.

Fig. 10 shows a comparison between the disturbances in the aeration system with disturbances from other locations, such as schemes of emergency control, bearings, excitation system, speed governor, pure water system, transformers and others.

How can be observed in Fig. 10, the disturbances due to aeration system was major than the others

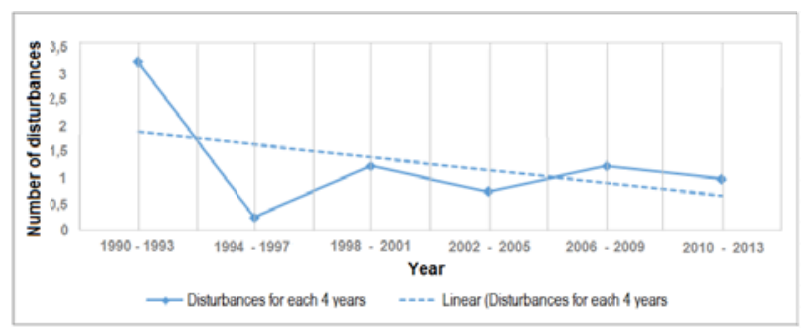

Fig. 9 Median of disturbances per year since 1990. 


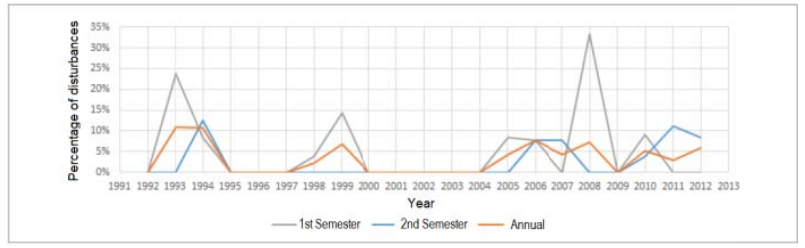

Fig. 10 Comparison of machine stoppage disturbances.

locations in some periods, reaching around 33\% more at 1 st semester of 2008.

\section{Conclusions}

The aeration valve, as well as the aeration system, are of great importance to avoid hydraulic instabilities and smooth the operational behavior of generating units in Itaipu. The several factors that can contribute to a catastrophic failure are reduced strongly when the aeration system is running properly.

As could be seen in Section 5, if the aeration system fails the consequences can be severe, therefore, good methods and procedures of maintenance are essential for constant improvement and consequent decreasing of the number of machine stoppage due to the aeration system.

The machine's tripping occurred in the analysed period can be due a lot of factors, such as the damping loss of the aeration valve, tightness loss of the obturator, total or partial loss of the pre-load of the valve's spring and accidental actuation from protections 71WA and 71AH and others. Thus, it is of extreme importance fully understanding the damage that each kind of fail causes so that more deep studies can be driven to the most critical components.

For better understanding of the action of the axial aeration system, a dynamic model of the aeration valve associated with a one dimensional dynamic model of the hydraulic system is being developed. These models will make possible an evaluation of the behavior of the entire hydraulic system about pressure fluctuation due the excitation provoked by the vortexes pulsation in the draft tube. This would allow the detection and behaviour analysis of the vortex due the valve actuation, making possible changes on aeration valve and at the protections settings. In addition, a complete three dimensional numerical model of the flow is also being developed and a comparison of the results of these models will be possible.

These settings, once unsuccessful attempted to be changed, the new possibility of reduction of the pressure in the aeration box is open the isolating valves of the aeration ducts by manual command. This procedure aims avoiding overcharge the anti-flooding system of the power house, case other abnormalities are presents, e.g., simultaneous failure at aeration valves of others generating units, what is possible during periods that downstream level is higher than normal. So, always the general situation permits, this procedure reduces the risk of water leakage to the generator interior after stoppages by failure on aeration systems.

The model created to simulate the vortex would allow great knowledge of its behaviour and allow studies for different methods and its eficiencies to reduced the effects caused at the ITAIPU turbines.

When comparing the disturbances in the aeration system with disturbances from other parts of the generator unit, it is possible to see a small, although considerable, presence of the aeration system, being responsible for $3.6 \%$ of machine stoppages from years 1991 to 2012.

\section{References}

[1] EIA (Electronic Industries Association), 2013. "International Energy Statistics." http://www.eia.gov/cfapps/ipdbproject/IEDIndex3.cfm?ti $\mathrm{d}=2$ pid=2aid=7.

[2] Itaipu. 2014. "ITAIPU Binacional.” http://www.itaipu.gov.br/energia/geracao.

[3] Fox, R. W., Pritchard, P. J., and McDonald's, A. T. 2011. Introduction to Fluid Mechanics. New York: John Wiley \& Sons.

[4] Marra, J. M. 1996. "Operation in Overload Regime of the Itaipu Turbines.” Presented at the XV SNPTEE-National Production and Electric Power Transmission Seminar, Foz do Iguaçu, Brazil.

[5] Itaipu. 1993. Hydraulic Stability Test-U09. Foz do Iguaçu: ITAIPU Binacional.

[6] Straatmann, R., Ferretti, A. P., Accattini, D. Q., Loreatto, 
Performance Analysis of the Aeration Valves and Its Protections at the Generating Units in ITAIPU Hydroelectric Power Plant

E., and Moretto, R. 2013. "Inteligent Control System of Aeration in Francis Turbines." Presented at the XV ERIAC-Regional meeting latin-american of the Cigré, Foz do Iguaçu, PR, Brazil.

[7] Marra, J. M. 2007. History of the Maintenance of the Aeration Valves of Itaipu's Turbines 01 to 18. Foz do Iguaçu: ITAIPU Binacional.

[8] Marra, J. M. 2005. Action Procedures after Actuation of
Protections 71WA 71AH against Presence of Water in the Air Intake Pipes and Drainage of Water from the Axial Aeration System of the Turbines. Foz do Iguaçu: ITAIPU Binacional.

[9] Marra, J. M. 2013. Feasibility Analysis of Operation's Philosophy Modification of the Isolating Valves V1 and V2. Foz do Iguaçu: ITAIPU Binacional. 